\title{
Distribution of fibronectin in normal and diseased human kidneys
}

\author{
AJ DIXON, J BURNS, MS DUNNILL, AND JO'D McGEE \\ From the Department of Pathology, University of Oxford, John Radcliffe Hospital, Headington, \\ Oxford $O X 39 D U, U K$
}

SUMMARY The distribution of fibronectin in 42 renal biopsies was investigated using an indirect immunoperoxidase technique on paraffin sections of formalin-fixed material. Biopsies were obtained from normal human kidneys and from patients with a variety of glomerular disorders. In normal glomeruli, fibronectin was present in Bowman's capsule, in the mesangium, and outlining peripheral capillary loops. A significant increase in fibronectin was observed in most types of glomerulopathy with a distribution closely related to the histopathological diagnosis. Fibronectin was diminished or absent in segmental scars, old diabetic nodules, and hyalinised glomeruli.

Fibronectin is a dimeric glycoprotein with a molecular weight of 450000 daltons. Two forms have been characterised, a soluble form present in plasma and other extracellular body fluids, originally isolated by Morrison et al. in $1948^{1}$ and called 'coldinsoluble globulin', and a form associated with the cell surface of a number of cultured cell lines, also known as 'large external transformation sensitive protein' (LETS). ${ }^{2}$ In vitro studies suggest that fibronectin is important in adhesion of cell to cell and cell to substratum. ${ }^{3}$ It binds specifically to fibrinogen and fibrin, ${ }^{4}{ }^{5}$ collagen, ${ }^{67}$ and heparin. ${ }^{8}$ In vivo, fibronectin and reticulin fibres co-distribute in most normal tissues. ${ }^{9}$ In models of experimental hepatic fibrosis produced by trauma or toxins, fibronectin and collagen are produced and deposited at the site of initial injury within hours, and both proteins are then incorporated into the resulting connective tissue septa (Burns et al., unpublished observations).

Recent immunohistochemical studies on glomerular fibronectin have demonstrated that it is a component of the mesangium of normal human glomeruli and is present in increased amounts in the expanded mesangium of a variety of glomerular disorders. ${ }^{10-12}$ While the observations of these authors for the most part concur, there are a few areas of disagreement. In normal human glomeruli, Pettersson and Colvin found fibronectin not only in the mesangium but also in capillary basement membranes, ${ }^{11}$ whereas Weiss et al. ${ }^{12}$ and Stenman and Vaheri $^{9}$ found it in mesangium alone. In ad-

Received for publication 31 March 1980 dition, the increased glomerular fibronectin in membranoproliferative glomerulonephritis noted by Pettersson and Colvin ${ }^{11}$ and Weiss et al. ${ }^{12}$ was contrary to the findings of Scheinman et al. ${ }^{10}$ The present study was undertaken in order to try to resolve some of these discrepancies.

\section{Material and methods}

Forty-two renal biopsies were included in the study. Of these, four biopsies were of normal renal tissue obtained from donor kidneys at the time of renal transplant. The remaining 38 were from patients with the following histopathological diagnoses: acute diffuse glomerulonephritis (3), minimal change (4), IgA nephropathy (3), focal segmental proliferative glomerulonephritis (6), diabetic nephropathy (5), mesangiocapillary (membranoproliferative) glomerulonephritis (4), membranous glomerulonephritis (4), malignant hypertension (3), amyloidosis (2), diffuse crescentic nephritis (3), and disseminated intravascular coagulation (1).

The isolation and characterisation of the fibronectin antigen and the rabbit anti-fibronectin IgG derived from it have been described elsewhere. ${ }^{1314}$

Immunohistochemical staining for fibronectin was conducted on sections of formalin-fixed, paraffinembedded renal tissue by an indirect immunoperoxidase technique following pepsin digestion. ${ }^{14}$ Dewaxed, hydrated $3 \mu \mathrm{m}$ paraffin sections were incubated for 10 minutes at $37^{\circ} \mathrm{C}$ in distilled water, followed by a further 2 hours' incubation at the same temperature in a $\mathbf{0 . 4 \%}$ solution of pepsin (Sigma Cat. 
No. P-7012) in $0.01 \mathrm{~N} \mathrm{HCl}$. After washing in running cold water for 10 minutes, the sections were rinsed in $0.01 \mathrm{M}$ phosphate buffered saline, $\mathrm{pH} 7.2$ (PBS), and treated with rabbit anti-fibronectin IgG (75 $\mu \mathrm{g} / \mathrm{ml}$ ) for 30 minutes at $22^{\circ} \mathrm{C}$. They were then washed twice in PBS and treated with a 1:50 dilution of horseradish peroxidase labelled swine antirabbit IgG (Dakopatts, Mercia Brocades Ltd) for a further 30 minutes at $22^{\circ} \mathrm{C}$. After further washings in PBS the horseradish peroxidase was developed with diaminobenzidine tetrahydrochloride and hydrogen peroxide in buffer. ${ }^{15}$ In some instances, staining for fibronectin was also performed by the indirect immunofluorescence technique on sections of snap-frozen renal tissue. These preparations were examined by epi-illumination using a Leitz Ortholux fluorescence microscope and blue light excitation.

Control sections in both procedures were incubated with either non-immune rabbit IgG or with fibronectin absorbed rabbit anti-fibronectin IgG. All sera, both immune and otherwise, were diluted with a $1-4 \%$ solution of ovalbumin in PBS.

\section{Results}

The results are summarised in the Table.

An identical staining pattern for fibronectin was observed in immunoperoxidase stained paraffin sections and corresponding immunofluorescent stained frozen sections. All controls were negative.

In normal kidney, fibronectin was present in mesangium and as a fine line around peripheral capillary loops of glomeruli (Figs 1 and 2). There was positive staining of Bowman's capsule and of the interstitium with a peritubular distribution. Vessel walls were stained most conspicuously on their intimal aspect. In one of the 'normal' renal biopsies, subcapsular renal cortex contained two ischaemic glomeruli which showed shrinkage but not total hyalinisation of the tuft and intracapsular fibrosis. These had increased fibronectin both withln the shrunken tuft and in the fibrosing capsule.

In all conditions associated with an expanded mesangium observable on routinely stained paraffin sections, there was a corresponding increase in mesangial fibronectin. This was most pronounced in acute diffuse glomerulonephritis (Figs 3 and 4), mesangiocapillary glomerulonephritis (Fig. 5), and diabetic glomerulopathy. In these three conditions there was also a considerable increase of fibronectin in peripheral capillary walls.

Only two of four cases of membranous glomerulonephritis showed increased fibronectin in thickened glomerular basement membranes (Fig. 6). In one of these cases it was unevenly distributed, being most marked on the endothelial aspect. The remaining two cases of membranous glomerulonephritis and all those with minimal change nephropathyo showed no significant difference in fibronectin distribution from normal kidneys.

All cases of crescentic glomerulonephritis had conspicuous staining for fibronectin between proliferating crescentic cells (Fig. 7). G̈lomerular tuft staining was variable.

Results* $^{*}$

\begin{tabular}{|c|c|c|c|c|c|c|}
\hline Diagnosis & $\begin{array}{l}\text { No. of } \\
\text { biopsies }\end{array}$ & Mesangium & $\begin{array}{l}\text { Glomerular } \\
\text { capillary wall }\end{array}$ & Vessels & Insterstitium & Special features \\
\hline Normal & 4 & + & + & + & + & $\begin{array}{l}1 \text { case with two ischaemic } \\
\text { glomeruli having }+++ \\
\text { mesangial staining }\end{array}$ \\
\hline $\begin{array}{l}\text { Acute diffuse } \\
\text { proliferative GN }\end{array}$ & 3 & $+t+$ & ++ & $\begin{array}{l}++(2) \\
+(1)\end{array}$ & $\begin{array}{l}++(1) \\
+(2)\end{array}$ & \\
\hline Minimal change & 4 & + & + & + & + & \\
\hline $\begin{array}{l}\text { Focal segmental } \\
\text { proliferative GN }\end{array}$ & 6 & + to $t++$ & + & + & $\begin{array}{l}+(4) \\
++(2)\end{array}$ & $\begin{array}{l}\text { Increased staining in seg- } \\
\text { mental lesions. One case with } \\
+++ \text { in crescents }\end{array}$ \\
\hline Diabetic & 5 & $+t$ to $t++$ & + to $t+t$ & + & + to ++ & $\begin{array}{l}\text { Early nodules }+++ \\
\text { Older nodules }+ \text { or }- \\
\text { Hyalinised glomeruli - }\end{array}$ \\
\hline $\begin{array}{l}\text { Mesangiocapillary } \\
\text { (membranoproliferative) }\end{array}$ & 4 & $+t+$ & +++ & + & ++ & \\
\hline Membranous & 4 & + & $+(2)++(1)+++(1)$ & + & $+(3)++(1)$ & \\
\hline Amyloid & 2 & - to $t+$ & - to ++ & $+\cdot$ & + & $\begin{array}{l}\text { Amyloid deposits negative } \\
++ \text { staining around them }\end{array}$ \\
\hline Malignant hypertension & 3 & - to +++ & + to ++ & + to ++ & ++ & $\begin{array}{l}\text { Negative segmental scars and } \\
\text { hyalinised glomeruli }\end{array}$ \\
\hline $\begin{array}{l}\text { Disseminated intravascular } \\
\text { coagulation }\end{array}$ & 1 & + & $+t$ & + & + & +++ intracapillary thrombi \\
\hline
\end{tabular}

*Assessment of fibronectin staining was graded subjectively on a scale - to +++ . Numbers in parentheses refer to the number of cases showing the change. 


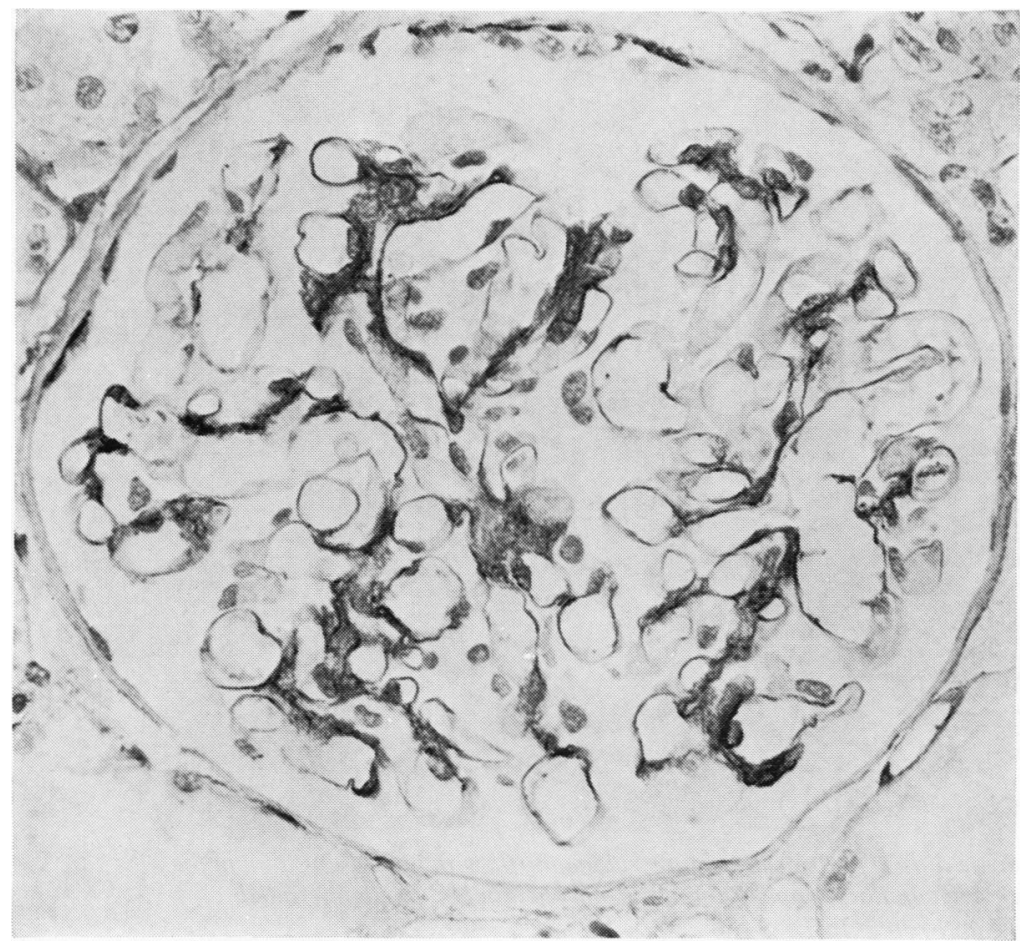

Fig. 1 Normal glomerulus showing staining for fibronectin in mesangium and capillary loops. Rabbit anti-fibronectin IgG and horseradish peroxidase labelled swine anti-rabbit IgG. $\times 480$

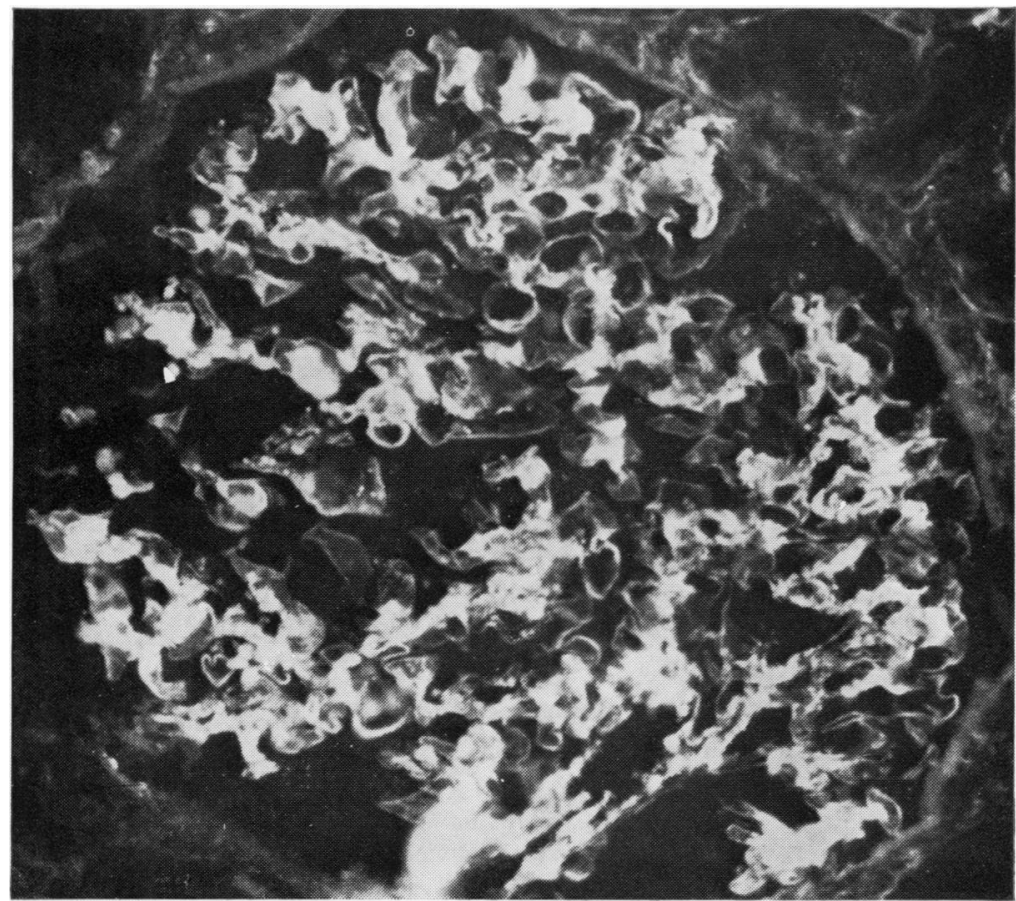

Fig. 2 Normal glomerulus showing fibronectin in mesangium and capillary loops. Rabbit antifibronectin IgG and FITClabelled swine anti-rabbit IgG. $\times 500$ 


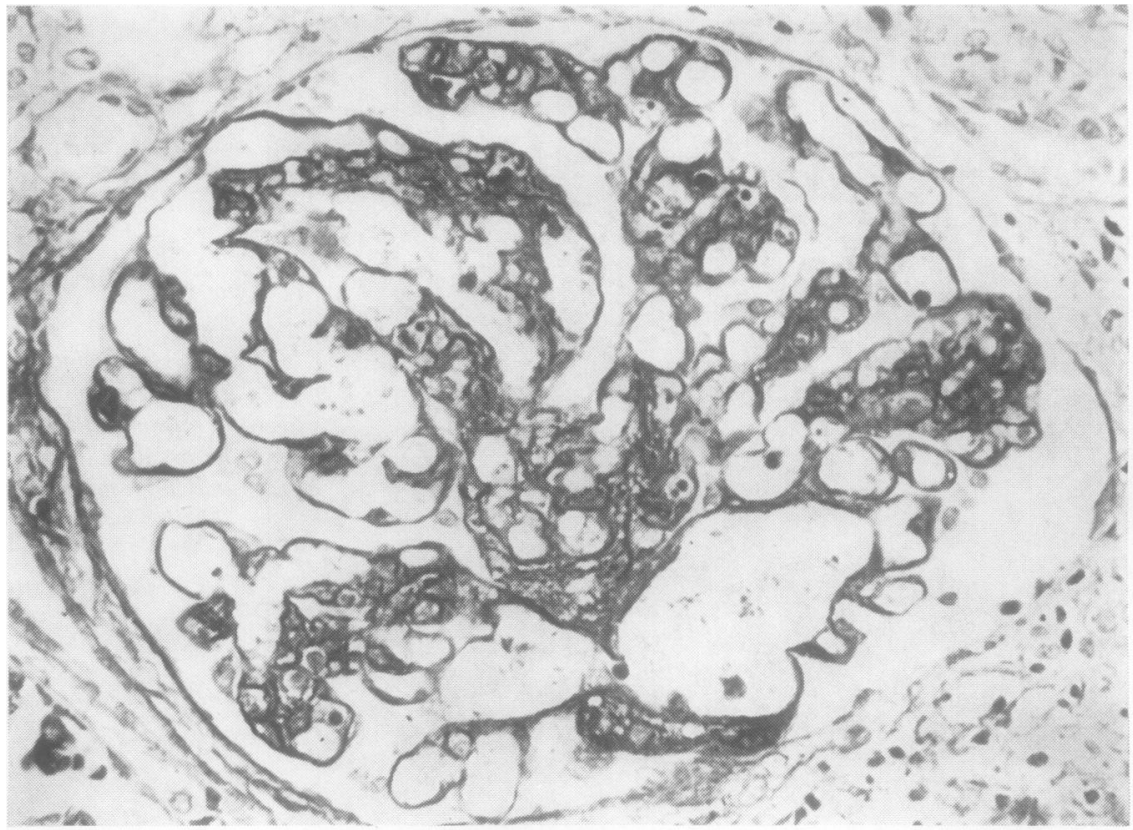

Fig. 3 Glomerulus in acute diff use proliferative glomerulonephritis with increased staining for fibronectin in mesangium and capillary loops. Rabbit anti-fibronectin IgG and horseradish peroxidase labelled swine anti-rabbit $\lg G . \times 480$

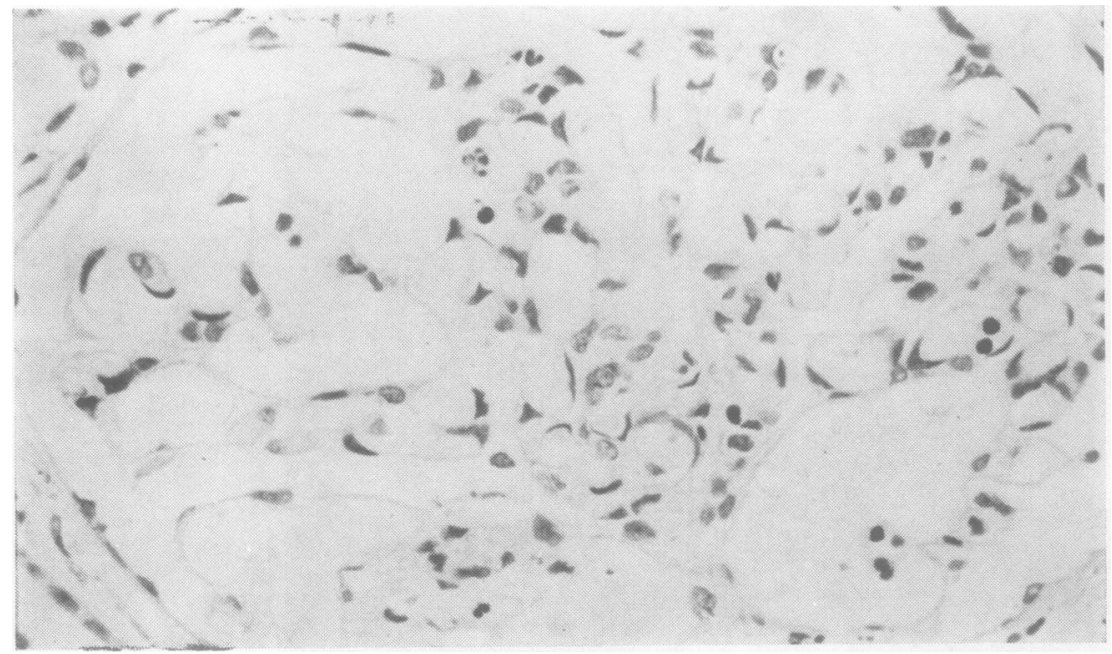

Fig. 4 Glomerulus in acute diffuse proliferative glomerulonephritis showing absence of staining with fibronectin-absorbed antiserum. Fibronectin-absorbed rabbit anti-fibronectin $I g G$ and horseradish peroxidase labelled swine anti-rabbit $\operatorname{IgG} . \times 480$ 


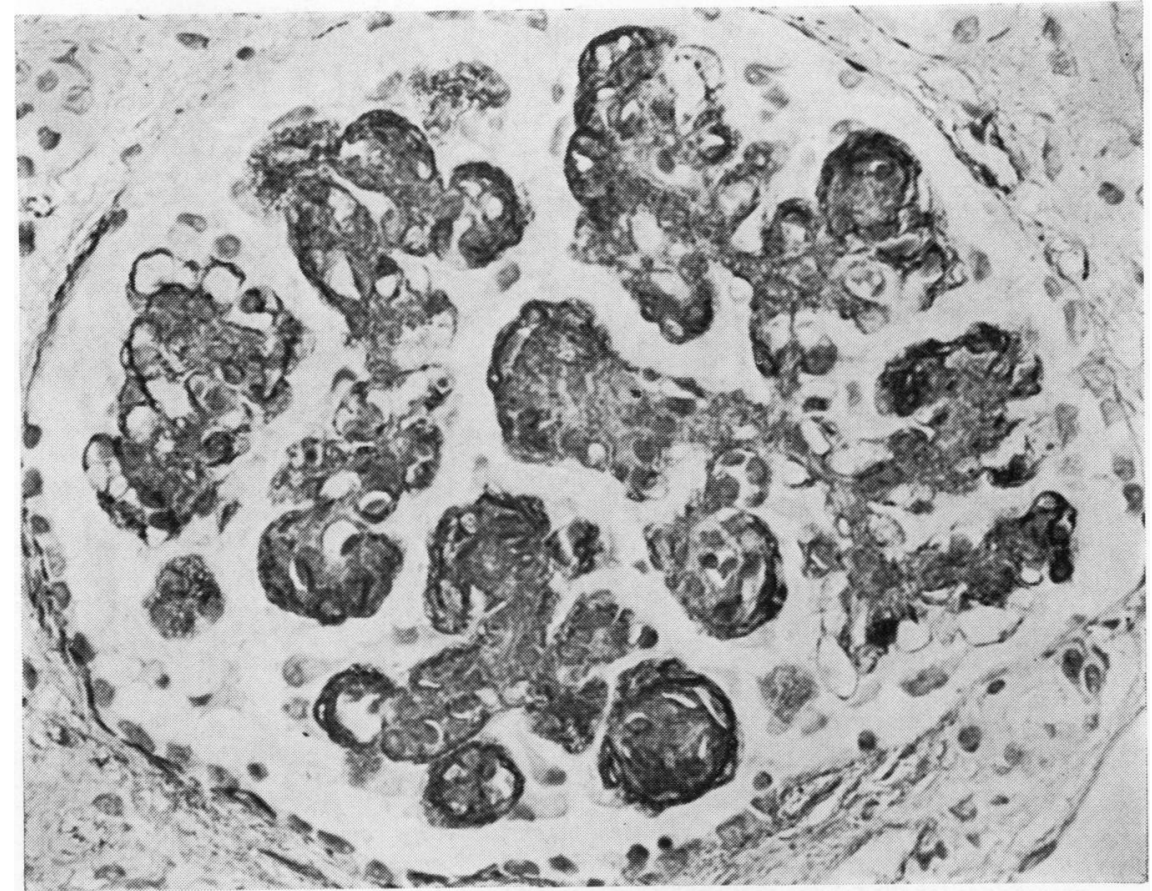

Fig. 5 Glomerulus in mesangiocapillary glomerulonephritis with increased mesangial and capillary wall staining for fibronectin. Rabbit anti-fibronectin IgG and horseradish peroxidase labelled swine anti-rabbit $\operatorname{IgG} . \times 480$

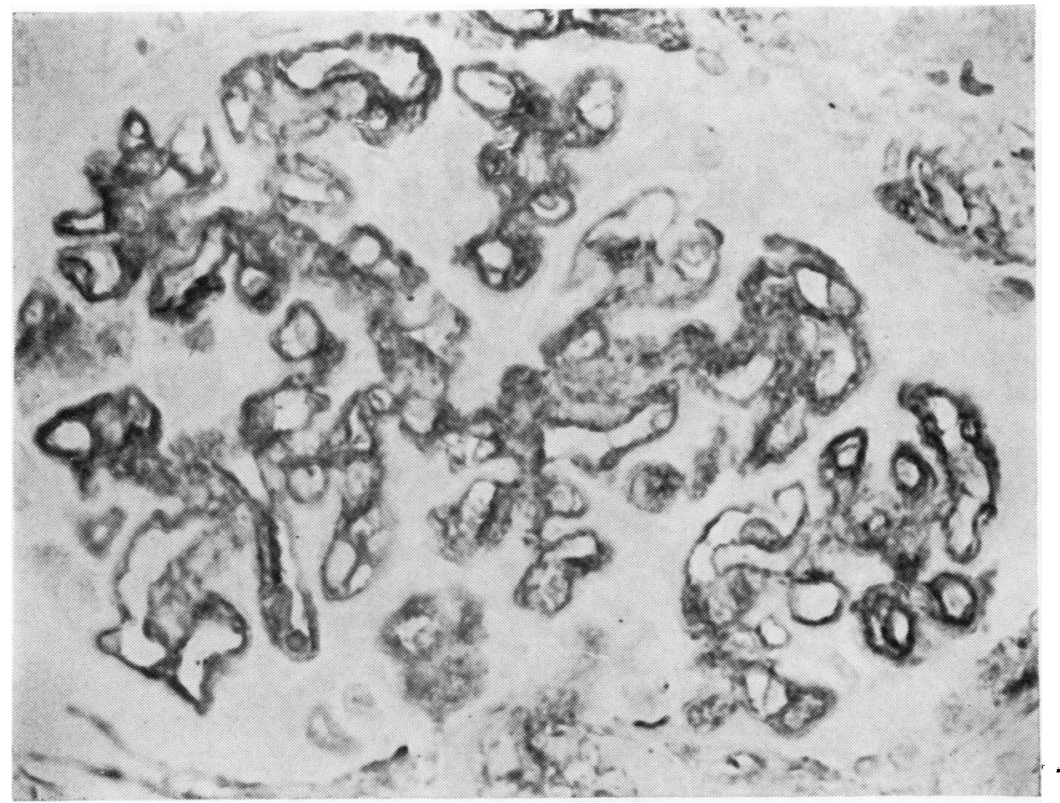

Fig. 6 Glomerulus in membranous glomerulonephritis with increased staining for fibronectin in peripheral capillary walls. Rabbit anti-fibronectin IgG and horseradish peroxidase labelled swine anti-rabbit IgG. $\times 480$ 


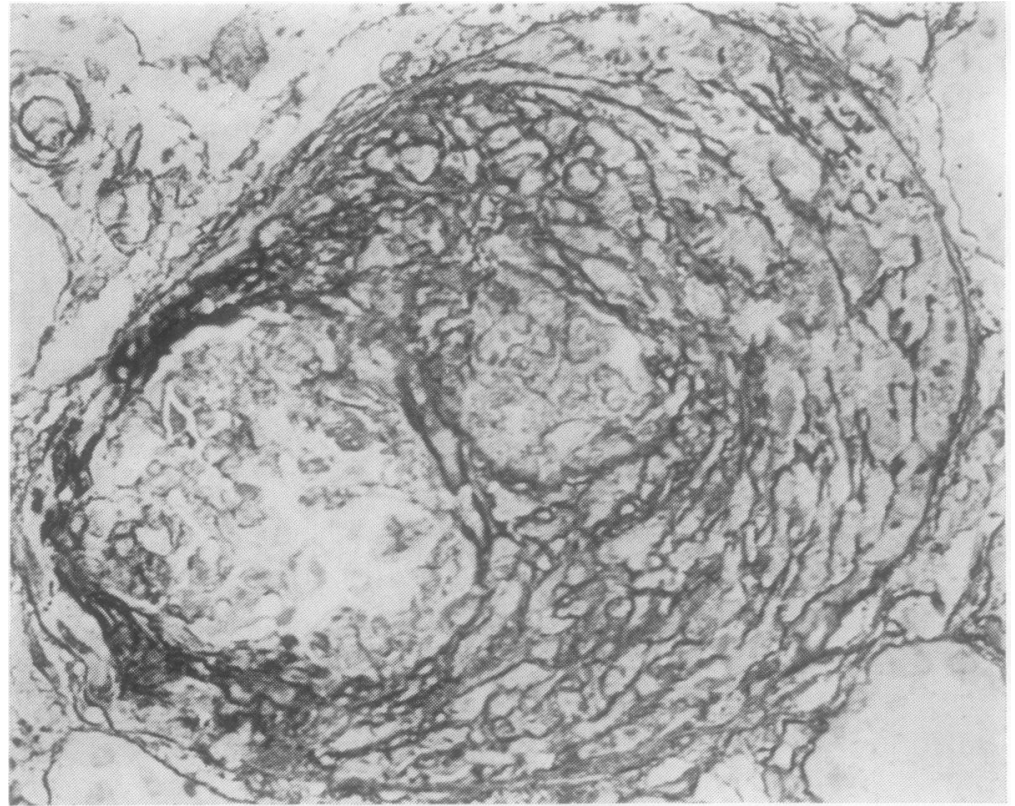

Fig. 7 Glomerulus in crescentic glomerulonephritis with strongly positive staining for fibronectin between crescentic cells. Rabbit anti-fibronectin IgG and horseradish peroxidase labelled swine anti-rabbit IgG. $\times 480$

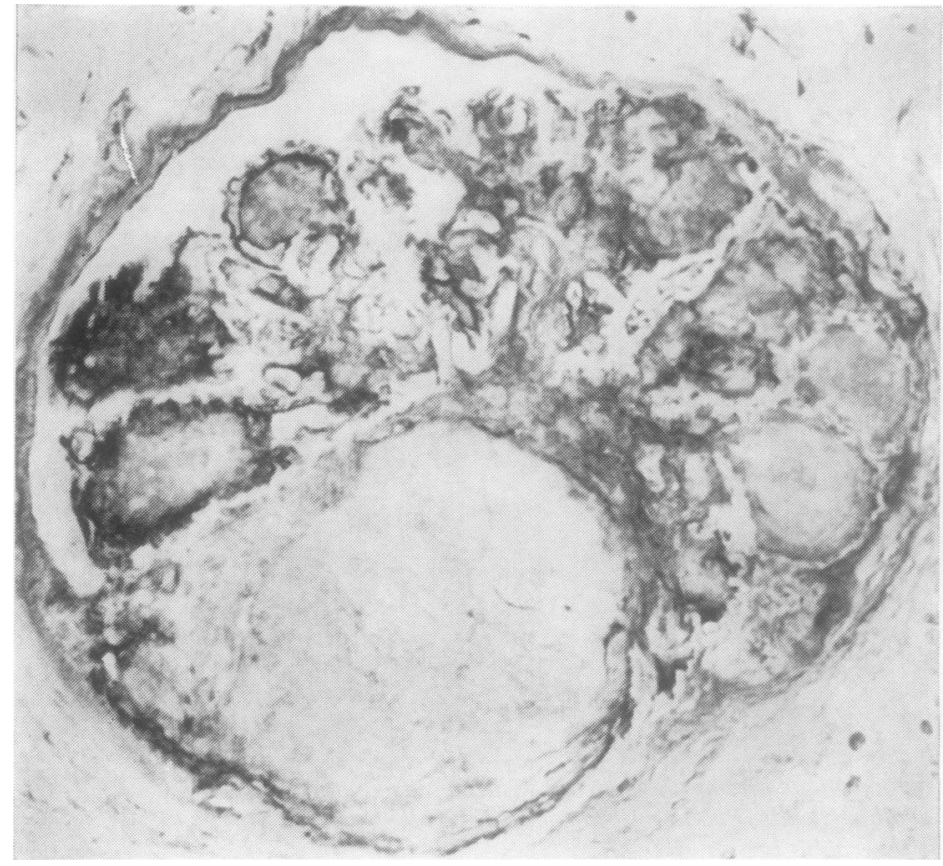

Fig. 8 Glomerulus in diabetic glomerulopathy showing a negatively stained large nodule and smaller nodules with varying degrees of positivity for fibronectin. Rabbit anti-fibronectin IgG and horseradish peroxidase labelled swine antirabbit IgG. $\times 480$ 
In renal amyloidosis, fibronectin surrounded the deposits of amyloid.

Hyalinised glomeruli, old segmental scars, and old diabetic nodules were all negative for fibronectin (Fig. 8). In contrast, glomeruli undergoing sclerosis, early segmental lesions, and some diabetic nodules (Fig. 8) were strongly positive for fibronectin.

Interstitial fibronectin was increased in severe glomerulonephritides and in end-stage renal disease. In vessels, fibronectin appeared to be concentrated in the intima. An increase was observed in intimal fibrosis and focally in small arteries and arterioles in malignant hypertension and acute diffuse glomerulonephritis.

\section{Discussion}

The distribution of fibronectin in normal and diseased human kidneys has previously been studied using immunological techniques applied to sections of frozen renal tissue. Formalin-fixed, paraffinprocessed renal tissue does not react with antibody to fibronectin without prior enzymic reactivation of the antigen. In this study this was achieved by exposure to a $0.4 \%$ pepsin solution. Subsequent immunohistochemical staining gave results identical with those produced by immunofluorescent staining of frozen sections and enabled a more precise localisation of fibronectin within optimally preserved renal tissue. The method also had the advantage of rendering more material available for investigation.

This study has confirmed some previous observations regarding renal fibronectin distribution and has provided additional evidence for its presence in peripheral capillary walls of normal human glomeruli. This observation corresponds with immunohistochemical demonstration at the ultrastructural level of fibronectin along cell surfaces abutting glomerular capillary basement membranes. ${ }^{16}$ Additional evidence is also provided for increased glomerular fibronectin in mesangiocapillary glomerulonephritis, as in other types of glomerulopathy with an expanded mesangium. The reason for previous slightly differing results is not clear, though it may be due, in part, to differing methods of fixation. ${ }^{11}$

The observation of negatively staining hyalinised glomeruli and old segmental scars ${ }^{10}$ has been confirmed, and, in addition, it was noted that ageing diabetic nodules lose their positivity for fibronectin. In all these situations the actively progressing lesion contains a considerable quantity of fibronectin, which gradually diminishes as scar tissue is laid down.

In the acute stages of damage, increased glomerular fibronectin may be present irrespective of the nature of the injurious process. Thus both ischaemi- cally and immunologically damaged glomeruli contain increased quantities. The two exceptions are minimal change glomerulonephritis and some cases of membranous glomerulonephritis where staining for glomerular fibronectin does not differ significantly from that in normal kidneys. This indicates that accumulation of fibronectin does not directly relate to the occurrence of proteinuria. Whether the increased amount in diseased glomeruli is derived from plasma or by local production is uncertain. The considerable quantities present in conditions such as acute diffuse proliferative glomerulonephritis suggest that it may be an exudative phenomenon and plasma-derived. An alternative hypothesis is that glomerular cells produce increased fibronectin as a non-specific response to injury. In this context, it is of interest to note that production of fibronectin by glomerular cells in culture has been demonstrated. ${ }^{16}$ Whatever its source, it may well account for part of the mesangial expansion in glomerulonephritis.

Since fibronectin has an affinity for fibrin, its presence in sites of fibrin deposition such as glomerular crescents and intracapillary thrombi might be predicted. This has been discussed by Pettersson and Colvin, who originally observed the considerable quantity to be found between proliferating crescentic cells. ${ }^{11}$

The role of fibronectin in relation to altered glomerular function in disease and in the reparative process requires further investigation. In vitro studies have suggested that it may be important in cell-collagen interaction and in collagen deposition. ${ }^{17}$ In the damaged glomerulus it might be involved in basement membrane regeneration or in the formation of scar tissue.

\section{References}

${ }^{1}$ Morrison PR, Edsall JT, Miller SG. Preparation and properties of serum and plasma proteins. XVIII. The separation of purified fibrinogen from fraction 1 of human plasma. J Am Chem Soc 1948;70:3103-8.

${ }^{2}$ Hynes RO, Bye JM. Density and cell cycle dependence of cell surface proteins in hamster fibroblasts. Cell 1974;3:113-20.

${ }^{3}$ Yamada KM, Olden K. Fibronectins-adhesive glycoproteins of cell surface and blood. Nature 1978;275:17984.

${ }^{4}$ Mosesson MW, Umfleet RA. The cold insoluble globulin of human plasma. I. Purification, primary characterization, and relationship to fibrinogen and other coldinsoluble fraction components. J Biol Chem 1970;245: 5728-36.

${ }^{5}$ Ruoslahti E, Vaheri A. Interaction of soluble fibroblast surface antigen with fibrinogen and fibrin: identity with cold-insoluble globulin of human plasma. J Exp Med $1975 ; 141: 497-501$.

- Engvall E, Ruoslahti E. Binding of soluble form of fibroblast surface protein, fibronectin, to collagen. Int $J$ Cancer 1977;20:1-5.

7 Engvall E, Ruoslahti E, Miller EJ. Affinity of fibronectin 
to collagen of different genetic types and to fibrinogen. $J$ Exp Med 1978;147:1584-95.

${ }^{8}$ Stathakis NE, Mosesson MW. Interactions among heparin, cold-insoluble globulin and fibrinogen in formation of the heparin-precipitable fraction of plasma. $J$ Clin Invest 1977;60:855-65.

${ }^{9}$ Stenman S, Vaheri A. Distribution of a major connective tissue protein, fibronectin, in normal human tissues. $J$ Exp Med 1978;147:1054-64.

${ }^{10}$ Scheinman JI, Fish AJ, Matas AJ, Michael AF. The immunohistopathology of glomerular antigens. II. The glomerular basement membrane, actomyosin, and fibroblast surface antigens in normal, diseased, and transplanted human kidneys. Am J Path 1978;90:71-84.

11 Pettersson EE, Colvin RB. Cold-insoluble globulin (fibronectin, LETS protein) in normal and diseased human glomeruli: papain-sensitive attachment to normal glomeruli and deposition in crescents. Clin Immunol Immunopathol 1978;11:425-36.

${ }^{12}$ Weiss MA, Ooi BS, Ooi YM, Engvall E, Ruoslahti E. Immunofluorescent localization of fibronectin in the human kidney. Lab Invest 1979;41:340-7.

${ }^{13}$ Sochynsky RA, Boughton BJ, Burns J, Sykes BC, McGee
JO'D. The effect of human fibronectin on plateletcollagen adhesion. Thrombosis Research. In press.

${ }^{14}$ Burns J, Dixon AJ, Woods JG. Immunoperoxidase localisation of fibronectin in glomeruli of formalin fixed paraffin processed renal tissue. Histochemistry. In press.

${ }^{15}$ Graham RC, Karnovsky MJ. The early stages of absorption of injected horseradish peroxidase in the proximal tubules of mouse kidney; ultrastructural cytochemistry by a new technique. J Histochem Cytochem 1966;14:291302.

${ }^{16}$ Oberley TD, Mosher DF, Mills MD. Localization of fibronectin within the renal glomerulus and its production by cultured glomerular cells. Am J Pathol 1979;96: 651-62.

17 Vaheri A, Mosher DF. High molecular weight, cell surface associated glycoprotein (fibronectin) lost in malignant transformation. Biochim Biophys Acta 1978;516:1-26.

Requests for reprints to: Dr AJ Dixon, Department of Histopathology, Level 1, John Radcliffe Hospital, Headington, Oxford OX3 9DU, UK. 